\title{
A Truncated Cardiac Troponin T Molecule in Transgenic Mice Suggests Multiple Cellular Mechanisms for Familial Hypertrophic Cardiomyopathy
}

\author{
Jil C. Tardiff, ${ }^{\star \|}$ Stephen M. Factor, ${ }^{\ddagger}$ Brian D. Tompkins, ${ }^{\|}$Timothy E. Hewett, ${ }^{\S}$ Bradley M. Palmer," Russell L. Moore, ${ }^{\natural}$ \\ Steve Schwartz, ${ }^{\S}$ Jeffrey Robbins, ${ }^{\S}$ and Leslie A. Leinwand \\ *Department of Medicine, Cardiology Division, Columbia University, College of Physicians and Surgeons, New York, New York \\ 10032; Department of Medicine, Albert Einstein College of Medicine, Bronx, New York 10461; ${ }^{\circledR}$ Children’s Hospital Research \\ Foundation, Department of Pediatrics, Division of Molecular Cardiovascular Biology, Cincinnati, Ohio 45229; and $\|_{\text {Department of }}$ \\ Molecular, Cellular and Developmental Biology, and "ㅁ Department of Kinesiology, University of Colorado, Boulder, Colorado 80309
}

\begin{abstract}
Mutations in multiple cardiac sarcomeric proteins including myosin heavy chain $(\mathrm{MyHC})$ and cardiac troponin $\mathrm{T}$ (cTnT) cause a dominant genetic heart disease, familial hypertrophic cardiomyopathy (FHC). Patients with mutations in these two genes have quite distinct clinical characteristics. Those with MyHC mutations demonstrate more significant and uniform cardiac hypertrophy and a variable frequency of sudden death. Patients with cTnT mutations generally exhibit mild or no hypertrophy, but a high frequency of sudden death at an early age. To understand the basis for these distinctions and to study the pathogenesis of the disease, we have created transgenic mice expressing a truncated mouse cTnT allele analogous to one found in FHC patients. Mice expressing truncated cTnT at low $(<5 \%)$ levels develop cardiomyopathy and their hearts are significantly smaller (18-27\%) than wild type. These animals also exhibit significant diastolic dysfunction and milder systolic dysfunction. Animals that express higher levels of transgene protein die within $24 \mathrm{~h}$ of birth. Transgenic mouse hearts demonstrate myocellular disarray and have a reduced number of cardiac myocytes that are smaller in size. These studies suggest that multiple cellular mechanisms result in the human disease, which is generally characterized by mild hypertrophy, but, also, frequent sudden death. (J. Clin. Invest. 1998. 101:2800-2811.) Key words: cardiomyopathy • troponin • myofibrils • mice $\bullet$ physiopathology
\end{abstract}

\section{Introduction}

Ordered assembly of multiple proteins into the sarcomere is a prerequisite of normal cardiac muscle contraction. A number of structural proteins of the sarcomere have been implicated in familial hypertrophic cardiomyopathy (FHC), ${ }^{1}$ including components of both the thick and thin filament systems (for a review see reference 1). FHC is an autosomal dominant disease

Address correspondence to Leslie A. Leinwand, Department of Molecular, Cellular and Developmental Biology, University of Colorado, Campus Box 347, Boulder, Colorado 80309. Phone: 303-4927606; FAX: 303-492-7606; E-mail: leinwand@stripe.colorado.edu

Received for publication 12 January 1997 and accepted in revised form 30 March 1998.

J. Clin. Invest.

(C) The American Society for Clinical Investigation, Inc. 0021-9738/98/06/2800/12 \$2.00

Volume 101, Number 12, June 1998, 2800-2811

http://www.jci.org characterized by frequent hypertrophy and is the most common cause of sudden death "on the field" in young athletes (2). Although it is not yet known how mutations in structural sarcomeric proteins cause this disease, it is thought that they operate through a common pathway, presumably by causing either a structural and/or functional alteration in the cardiac sarcomere. At least seven different genes and multiple alleles within genes cause FHC, but they all encode highly abundant structural proteins. Despite the fact that all FHC alleles occur in structural proteins, the disease is clinically heterogeneous. Affected individuals within and among families demonstrate highly diverse clinical phenotypes. For example, there is much more significant hypertrophy in patients with myosin heavy chain (MyHC) mutations than in patients with cardiac troponin $\mathrm{T}(\mathrm{cTnT})$ mutations $(3,4)$. In contrast, patients with cTnT mutations have a significantly higher incidence of sudden death than patients with MyHC mutations $(4,5)$. The basis for this difference is not yet known.

To understand the pathogenesis of FHC, both biochemical and transgenic mouse analyses have been undertaken. Three mutant MyHC alleles have been characterized in in vitro biochemical studies and two of the three alleles studied have reduced actin-activated ATPase activity, indicating a defect in the motor activity of the myosin molecule (6). One of these defective alleles has been tested in an in vitro motility assay for its dominant effect on wild-type (WT) myosin by mixing the mutant and WT proteins. The mutant myosin inhibited the motile activity of the WT protein disproportionately, suggesting a dominant negative mechanism of action (7). Transgenic mice expressing two different MyHC mutations in their hearts have been produced, and exhibit somewhat distinct phenotypes with respect to hypertrophy $(8,9)$. However, many of the other clinical features of the disease are replicated in one or both of the mouse models.

Less is known about the molecular pathogenesis of cTnTbased FHC. cTnT is one of three subunits of troponin, the complex of which regulates muscle contraction via $\mathrm{Ca}^{2+}$ binding to troponin $\mathrm{C}(\mathrm{TnC})$. The primary role of $\mathrm{TnT}$ is thought to be to promote assembly of the troponin-tropomyosin complex onto the actin filament. TnT binds to, or interacts directly with, tropomyosin, actin, $\mathrm{TnC}$, and troponin I. Nine mutations have been described in cTnT that cause FHC, including seven missense mutations, a deletion of an internal amino acid and a

1. Abbreviations used in this paper: BDM, 2,3-butanedione monoxime; cTnT, cardiac troponin T; FTC, familial hypertrophic cardiomyopathy; H\&E, hematoxylin and eosin; LV, left ventricle; MAP, mean arterial pressure; MyHC, myosin heavy chain; NGS, normal goat serum; TnC, troponin C; WT, wild type. 
splice-site mutation that would result in the loss of either the 14 or 28 carboxy-terminal residues with the addition of seven non-cTnT amino acids in the latter case $(4,5,10)$. Given that such a truncated mutant structural protein might be unstable, one mechanism for pathogenesis might be haploinsufficiency (11). However, cell biological and biochemical analysis of two mutant and wild-type cTnT alleles suggest that the truncated cTnT is stable and behaves as a dominant negative mutation (12; our study). These studies have provided some insight into the functional implications of these mutations. The truncated cTnT FHC allele causes a reduction in contractile force when expressed in quail myotubes, as well as a regional disruption in sarcomeres (12). The mutant showed a clear incorporation into the myofibril, suggesting that this function of cTnT was not defective, consistent with a dominant negative mode of action. In a biochemical study, an FHC missense mutation (Arg $92 \mathrm{Gln}$ ) in cTnT was shown to bind normally to thick and thin filament components, but actually increases the velocity of movement of thin filaments on myosin (13).

One of the more intriguing aspects of the molecular genetic and clinical characterizations of FHC is the observation that mutations in the motor protein, myosin, generally result in significant hypertrophy and a highly variable frequency of sudden death, whereas mutations in the thin filament protein, cTnT, generally result in mild or no discernable hypertrophy and frequent sudden death. By creating transgenic mice expressing a cTnT allele with a carboxy-terminal truncation, we have found that the hearts from these mice are smaller than WT because of a primary loss of myocytes and a decrease in myocyte cell size. In addition, these animals exhibit significant diastolic dysfunction. Transgenic mice, expressing $<10 \%$ of their total cTnT as the mutant form, die within hours of birth.

\section{Methods}

Clone construction and screening. A full-length (1,089 nt) adult mouse cTnT cDNA clone was isolated from a BALB/c mouse cardiac lgt11 cDNA library (Clontech, Palo Alto, CA) and cloned into Bluescript KS + (Stratagene Cloning Systems, La Jolla, CA). The full-length cDNA (WT) was tagged with an 11aa human c-myc epitope (14) via PCR using Vent DNA polymerase (New England Biolabs, Beverly, MA). The $5^{\prime}$ oligonucleotide (containing sequence for the c-myc tag and MluI-EcoRI restriction sites): ACGCGTGAATTCTAATGGTGGAGCAAAAGCTCATTTCTGAAGAGGAGGACTTGTCTGACGCCGAGGAGGTGGTG was paired with the $3^{\prime}$ oligonucleotide CCGAAGCTTTCATCATTTCCAACGCCCGGTGACTTTG. The resultant DNA fragment was subcloned into Bluescript and the sequence verified by Thermal Cycle Sequencing. The truncation construct was generated by a two-step process. First, the truncated $3^{\prime}$ end was generated via PCR using the WT-Bluescript clone as a template with the internal 5' oligonucleotide CGGAATTCTGGCCATCGACCACCTGAAT and the $3^{\prime}$ primer GGAATTCCTAGCCTTCCCGCGGGTCTTGGAGTTCGTATTTCTGCTGCTTGAAC. The resultant fragment was subloned into Bluescript, sequenced, and reisolated as a MscI-EcoRV fragment. The original WT-Bluescript construct was digested with MscI and EcoRV to isolate a WT 5' end. The $5^{\prime}$ fragment was ligated to the truncated $3^{\prime}$ end generated above to result in a $5^{\prime}$ myc-tagged cTnT-truncation construct (cTnT-Myc-truncation). Both the WT and truncation Bluescript constructs were digested with MluI-EcoRV and the isolated fragments were individually ligated to a preexisting "Cardiac Transgenic Vector" containing $-2,996 \mathrm{bp}$ of $5^{\prime}$ upstream sequence from the rat $\alpha \mathrm{MyHC}$ promoter and $1,500 \mathrm{bp}$ of the mouse $\beta^{\text {maj }}$ globin terminator (15) separated by a multiple cloning site. The resultant transgene constructs were di- gested with $\mathrm{KpnI}$ to isolate a 5.5-kb linear fragment and used in microinjections. Transgenes were injected into the pronuclei of CBA/B6 fertilized mouse eggs derived from an $\mathrm{F} 1$ cross between FVB/N and C57/B6 strains (16). Founders were screened via Southern analysis of tail DNA using a 650-bp internal cDNA probe derived from the original full-length cDNA as shown in Fig. 1. All F1 and subsequent screenings were performed via PCR using a pair of transgene-specific primers: $5^{\prime}$ ( $\alpha$ Promoter) ACCTAGAGGGAAAGTGTCTT and 3' (Myc-TnT) TCCTCTTCAGAGATGAGCTTT. All PCR reactions contained the internal control housekeeping primers Mus1: TGAGGTTGTCTTCTGATCTGC and Mus2: TCCTGGACAAAGTAACCCTTG.

Protein isolation and western analysis. Mice were killed via cervical dislocation and the excised hearts were immediately washed in ice-cold buffer A $\left(50 \mathrm{mM} \mathrm{KCl}, 10 \mathrm{mM} \mathrm{KPO}_{4}, 2 \mathrm{mM} \mathrm{MgCl} 2,0.5 \mathrm{mM}\right.$ EDTA, $2 \mathrm{mM}$ DTT, and $0.1 \mathrm{mM}$ PMSF) on ice (17). Excess tissue was carefully trimmed and the heart was homogenized in $10 \mathrm{vol}$ of buffer A. Approximately $30 \%$ of the resultant homogenate was removed and subjected to a 10-min spin at $14 \mathrm{~K}\left(4^{\circ} \mathrm{C}\right)$ in an Eppendorf microfuge. The supernatant was removed and the remaining pellet was carefully resuspended in an equal volume of buffer A. Protein concentrations were determined for each fraction via a Lowry assay (Bio-Rad, Hercules, CA) and diluted to a final concentration of $1 \mathrm{mg} / \mathrm{ml}$ in Laemmli buffer (18). Samples were aliquoted and stored at $-80^{\circ} \mathrm{C}$ until use. Protein samples were subjected to electropheresis on a $10 \%$ SDS-PAGE gel and transferred to $0.2 \mathrm{~mm}$ nitrocellulose. The blots were blocked in $10 \%$ nonfat dry milk in PBS for $2 \mathrm{~h}$ at room temperature. Blots were incubated in a monoclonal antibody against cTnT (Sigma Chemical Co., St. Louis, MO) or c-myc epitope, 9E10.2 (American Tissue Culture Collection, Rockville, MD) at a dilution of 1:500 or 1:5,000, respectively, in $5 \%$ BSA overnight at $4^{\circ} \mathrm{C}$. After primary antibody incubations, three washes in PBS were followed by incubation in the secondary antibody, peroxidase-conjugated goat antimouse IgG (Jackson Laboratories, West Grove, PA) diluted 1:5,000 in $10 \%$ nonfat dry milk in PBS for $2 \mathrm{~h}$ at room temperature. The blots were then washed three times in $0.05 \%$ NP-40/PBS. Bands corresponding to cTnT and myc-cTnT were visualized using the Renaissance Western Blot Chemiluminescence Reagent (NEN Life Sciences, Boston, MA).

Myofibril preparation and electrophoresis. Mice were humanely killed and the hearts were immediately excised and rinsed in ice-cold $0.9 \% \mathrm{NaCl}$. All of the following procedures were performed on ice and represent a minor modification of the procedure described in reference 17. Four hearts per line were isolated (animals were age matched) and individually minced in $1 \mathrm{ml} /$ heart of $\mathrm{K} 60$ buffer $(60 \mathrm{mM}$ $\mathrm{KCl}, 20 \mathrm{mM}$ Mops, pH 7.0, $2 \mathrm{mM} \mathrm{MgCl}$, $0.2 \mathrm{mM}$ PMSF, $0.5 \mathrm{mg} / \mathrm{ml}$ leupeptin, and $0.5 \mathrm{mg} / \mathrm{ml}$ pepstatin A). Samples were then homogenized with a tissumizer at $10,000 \mathrm{~g}$ for 4-5 minutes followed by a 15 min centrifugation at $15,000 \mathrm{~g}$ in a Beckman ${ }^{\circledR}$ JA-20 centrifuge (Fullerton, CA). The supernatant was removed and the pellet dispersed by homogenization in $4 \mathrm{ml}$ of $\mathrm{K} 60$ at $8,000 \mathrm{~g}$ for 3-4 min followed by a 10 -min spin at 5,000 $\mathrm{g}$. The pellet was again homogenized (at 5,000 $\mathrm{g}$ for 2-3 min), however, EGTA, pH 7.0, was added to the K60 buffer to a final concentration of $1 \mathrm{mM}$. The pellet was isolated via centrifugation at 5,000 $\mathrm{g}$ for $10 \mathrm{~min}$ and subsequently extracted with Triton X-100 as follows: Triton X-100 was added to the above K60 + EGTA solution to a final concentration of $1 \%$. Each pellet was carefully resuspended in $4 \mathrm{ml} \mathrm{K60}+$ EGTA + Triton buffer and homogenized at $5,000 \mathrm{~g}$ for $30 \mathrm{~s}$. Samples were incubated on ice for $1 \mathrm{~h}$ and redispersed every $10 \mathrm{~min}$ by homogenization at $5,000 \mathrm{~g}$ for $30 \mathrm{~s}$. Samples were recentrifuged at 5,000 $\mathrm{g}$ for $10 \mathrm{~min}$ and the extraction was repeated once. The subsequent pellet (now white in color) was gently dispersed by homogenization at 2,500 $\mathrm{g}$ for $30 \mathrm{~s}$ in $4 \mathrm{ml} \mathrm{K} 60$ (alone) and isolated by centrifugation at $5,000 \mathrm{~g}$ for $10 \mathrm{~min}$. This step was repeated once and the final pellet was isolated by centrifugation at $10,000 \mathrm{~g}$ for $10 \mathrm{~min}$. The pellet was gently resuspended in $0.5 \mathrm{ml}$ of $\mathrm{K} 60$ and protein concentration was determined by a modified Lowry assay. Myofibrils were diluted to a final concentration of $2 \mathrm{mg} / \mathrm{ml}$ in 
K60 buffer and sodium azide was added to a final concentration of $10 \mathrm{mM}$. Samples were subsequently aliquoted in Laemmli buffer $\left(1 \mathrm{mg} / \mathrm{ml}\right.$ final) and stored at $-70^{\circ} \mathrm{C} .5 \mu \mathrm{g}$ of each myofibril sample was subjected to SDS-PAGE (12\% gels) as described above. Gels were subsequently stained with Coomassie blue for $3 \mathrm{~h}$ and destained overnight.

Northern blot analysis. Isolation of total RNA from mouse hearts was performed as described by Chomczynski et al. (19). $10 \mu \mathrm{g}$ of total RNA from each source was separated on a $0.8 \%$ agarose-formaldehyde gel, transferred to a nylon membrane (ICN Biomedicals, Irvine, $\mathrm{CA}$ ), and sequentially hybridized with a series of radiolabeled DNA probes. Unique single-stranded oligonucleotide sequences corresponding to $\alpha \mathrm{MyHC}$ (5'-GAGGGTCTGCTGGAGAGG-3') and $3 \mathrm{MyHC}$ (5'-TGTTGCAAAGGCTCCAGGTCTGAGGGCTTC-3') were end-labeled and added to hybridization solution comprised of $7 \%$ SDS, $10 \times$ Denhardt's solution, $20 \mathrm{mM} \mathrm{NaPO}_{4}$, pH 7.2, $5 \times \mathrm{SSC}$, and $0.2 \mathrm{mg} / \mathrm{ml}$ denatured salmon sperm DNA. The blots were hybridized overnight at $55^{\circ} \mathrm{C}$. Sequential washes were performed $(2 \times \mathrm{SSC} /$ $0.1 \% \mathrm{SDS}, 1 \times \mathrm{SSC} / 0.1 \% \mathrm{SDS}, 0.5 \times \mathrm{SSC} / 0.1 \% \mathrm{SDS})$ at $42^{\circ} \mathrm{C}$ and the blots were exposed overnight with an intensifying screen at $-70^{\circ} \mathrm{C}$. Restriction fragments of GAPDH, mouse cTnT, and SERCA2 cDNA sequence were isolated and labeled via random priming. Hybridizations were performed overnight at $65^{\circ} \mathrm{C}$ in the following hybridization solution: $5 \times$ SSC, $1 \times$ Denhardt's solution, $10 \%$ Dextran sulfate, $50 \%$ formamide, $1 \%$ SDS, and $0.2 \mathrm{mg} / \mathrm{ml}$ denatured salmon sperm DNA. Washes were performed as described above at $65^{\circ} \mathrm{C}$ and with an added wash with $0.1 \times \mathrm{SSC} / 0.1 \%$ SDS. Blots were exposed overnight with an intensifying screen at $-70^{\circ} \mathrm{C}$.

Myocyte density determination. Neonatal mice from both lines 117 and 191 along with non-Tg siblings were humanely killed and their hearts were immediately excised and rinsed in ice-cold PBS. Each heart was subsequently infused in a stepwise fashion with a sucrose/PBS solution (10-20-30\%) on ice for 10, 20, and $60 \mathrm{~min}$, respectively. The infused hearts were then embedded in Tissue-Tek OCT (Miles, Elkhart, IN) and quick-frozen in isopentane cooled in liquid nitrogen. Hearts were stored at $-80^{\circ} \mathrm{C}$ until sectioning. Each heart was sectioned on a cryostat $(4 \mathrm{mM})$ and the sections were stored at $-80^{\circ} \mathrm{C}$ in airtight containers until use. Sections were postfixed in icecold $3.7 \%$ formaldehyde/PBS for $10 \mathrm{~min}$. After a 10-min wash in PBS, sections were blocked and permeabilized in $10 \%$ normal goat serum (NGS)/0.5\% Triton X-100/PBS for $1 \mathrm{~h}$ at room temperature. The sections were stained with the anti-sarcromeric MyHC antibody F59 in $1 \% \mathrm{NGS} / 0.05 \%$ Triton $\mathrm{X}-100$ for $1 \mathrm{~h}$ at room temperature. Any RNA, which would create cytoplasmic background when counterstaining with propidium iodide, was destroyed by including $100 \mathrm{mg} / \mathrm{ml}$ DNAse free RNAse (Boehringer Mannheim, Indianapolis, IN) in the primary antibody incubation. After three 5-min washes in PBS, sections were incubated for $1 \mathrm{~h}$ at room temperature in the secondary antibody, FITC-conjugated goat anti-mouse IgG (Jackson Laboratories) diluted $1: 40$ in $1 \%$ NGS $/ 0.05 \%$ Triton X-100/PBS. Sections were washed once in PBS and then counterstained with $7.5 \mathrm{mg} / \mathrm{ml}$ propidium iodide (Molecular Probes, Eugene, OR) for $15 \mathrm{~min}$ at room temperature. Directly after counterstaining, the sections were washed three times in PBS, washed once in distilled $\mathrm{H}_{2} \mathrm{O}$, and mounted in $200 \mathrm{mg} / \mathrm{ml} \mathrm{DABCO} / \mathrm{Gelvitol}$. Slides were kept in the dark at $4^{\circ} \mathrm{C}$ until use.

Confocal microscope images of the sections were taken on a Molecular Dynamics Multiprobe 2001 CLSM. This scope uses an argon laser, a 530DF30 filter for the FITC channel, and a 600EFLP filter for the propidium iodide channel. Scanned areas were selected using only the propidium iodide-emitting red channel. This eliminated possible bias for areas which might have seemed to contain fewer myocytes. Each section was scanned in four different quadrants. For each line of mice, two unrelated mice were used for a total number of eight images per mouse line. Scan areas in the nontransgenic sections were picked completely at random whereas transgenic scan areas were selected based on the appearance of myocellular disarray. Dual scans showing both myosin stain (FITC) and propidium iodide counterstain were created. These dual scans were counted for the total number nuclei per field and total number of myocytes per field. Counting of nuclei and myocytes was done independently by two different individuals in a blind manner. Total number of nuclei per field was obtained by counting propidium iodide-stained nuclei. Nonmyocytes were tabulated by counting the number of nuclei not surrounded by cytoplasmic myosin. This number was used to calculate myocyte totals by subtracting nonmyocytes from the total number of nuclei. All values were analyzed via a Student's $t$ test.

Isolated perfused working heart preparation. These studies were carried out as previously described (20). Briefly, age-matched male mice (23 wk of age) from the same litter (Tg and non- $\mathrm{Tg}$ ) were compared. Animals were humanely killed and the hearts immediately excised. A 20-gauge cannula was tied onto the aortic stump to allow regulation and recording of mean arterial pressure (MAP) (Starling resistance) and aortic flow (Transonic Flow Probe Model T206; Transonic Systems Inc., Ithaca, NY). A silastic fluid-filled catheter was tied into the left pulmonary vein to accommodate regulation on recording of venous return (cardiac output). The catheter was completely water-jacketed for improved temperature $\left(37.4^{\circ} \mathrm{C}\right)$ regulation of the Krebs-Henseleit solution that was returned to the left side of the heart for anterograde perfusion. Left ventricular pressure was measured as systolic, diastolic, and end-diastolic pressure. The recording, amplification, and differentiation systems used were the DigiMed Systems Analyzers BPA-2000, HPA-200, HPA-210, and LPA-200 (Micro-Med, Inc., Louisville, KY). The fluid-filled catheter system responded well within experimental requirements without distortion up to a frequency of $600 \mathrm{bpm}$. Custom designed software calculated heart rate, MAP, left ventricular pressure, peak systolic pressure, time to peak pressure, half time of relaxation, the first derivatives of the change in left ventricular systolic pressure with respect to time $( \pm \mathrm{dP} / \mathrm{dt})$, aortic and coronary flow, venous return $(\mathrm{CO})$, left ventricular minute work $(\mathrm{MAP} \times \mathrm{CO})$, stroke volume $(\mathrm{CO} / \mathrm{HR})$, stroke work $(\mathrm{SV} \times \mathrm{MAP})$, left atrial pressure, and perfusate temperature. The arterial $\mathrm{PO} 2$ was $650 \mathrm{mmHg}$ and the $\mathrm{pCO}_{2} \sim 30 \mathrm{mmHg}$. The data is expressed as mean \pm SEM. Starling curves were generated by linear regression using Statview ver 4.01 (Abacus Concepts Inc., Berkeley, CA).

Adult myocyte isolation and video imaging. Cardiac myocytes were obtained from the ventricles and septal free wall by a modified method previously described in detail $(21,22)$. Heparinized animals ( $250 \mathrm{U}$ ) were anesthetized with $\sim 35 \mathrm{mg} / \mathrm{kg}$ body weight sodium pentobarbital (Nembutal, Abbot Laboratories, Abbot Park, IL) after which the hearts were rapidly excised and placed in ice-cold saline. A modified Langendorf perfusion apparatus was used to perfuse the hearts in a retrograde fashion with a bicarbonate-based, nominal $\mathrm{Ca}^{2+}$-containing solution. After $4 \mathrm{~min}$, the perfusate was switched to a solution containing collagenase Type II (Worthington Biochemical Corporation, Freehold, NJ). All solutions were maintained at $\mathrm{pH}$ 7.4, and $37^{\circ} \mathrm{C}$, and were constantly bubbled with $95 \% \mathrm{O}_{2} / 5 \% \mathrm{CO}_{2}$ gas. Additionally, all buffers and growth media contained $10 \mathrm{mM}$ 2,3butanedione monoxime (BDM) (Sigma Chemical Co.). The heart was detached from the Lagendorf apparatus and the atria were removed leaving the ventricles and septum, which were then minced and placed in a $10-\mathrm{mM} \mathrm{Ca}^{2+}$-buffered saline solution. The tissue was teased for $7 \mathrm{~min}$ using heat-blunted Pasteur pipettes. The crude tissue suspension was transferred by filtration through a 270 nylon mesh to a $15-\mathrm{ml}$ sterile conical tube and the myocytes were allowed to settle for $7 \mathrm{~min}$. The pellet was then rinsed in succession with a $100-\mathrm{mM}$ $\mathrm{Ca}^{2+}$ and a $200-\mathrm{mM} \mathrm{Ca}^{2+}$-containing buffered saline solution. Isolated cardiac myocytes were suspended in the bicarbonate-based growth media and plated onto laminin-coated (both from Sigma Chemical Co.) glass coverslips for incubation for $2 \mathrm{~h}$ at $37^{\circ} \mathrm{C}$ and $5 \%$ $\mathrm{CO}_{2}$ to allow for cell attachment. After $2 \mathrm{~h}$, a coverslip was removed from the incubator and placed under an inverted microscope with a $40 \times$ objective. All myocytes, which were striated and whose edges were unobstructed, were recorded onto videotape. Myocyte length, projected width, and area were determined using a video frame grab- 
ber and National Institutes of Health (Bethesda, MD) Image 1.4 software. These variables were compared between transgenic and nontransgenic sibling mice by way of the Student's $t$ test.

\section{Results}

Generation of cTnT-Myc-WT and cTnT-Myc-truncation transgenic mice. FHC is a dominant disorder in which most affected individuals are heterozygous, so that the creation of an animal model could be accomplished by transgenesis in which the TnT mutant transgene will exist on a WT mouse background. As shown in Fig. $1 \mathrm{~A}$, two transgenic constructs were generated to express either a WT mouse cTnT or a cTnT molecule that corresponds to a truncation allele previously described in FHC patients (11). Both alleles were myc-tagged at their amino termini. All of the mutant sites in cTnT implicated in the development of FHC in humans are conserved in the mouse cTnT sequence. One of the human cTnT FHC alleles involves a splice-site donor mutation $(\mathrm{G} \rightarrow \mathrm{A}$ at residue 1 of Intron 15), which results in a frameshift and subsequent premature termination (11). The resulting mRNA encodes a pro- tein missing the $\mathrm{COOH}$-terminal 28-amino acids (Exons 15 and 16) with an additional seven novel residues before termination. A murine cTnT cDNA incorporating these predicted alterations (cTnT-Myc-truncation) was constructed and, along with the cTnT-Myc-WT sequence, was used to develop several lines of transgenic mice. Cardiac myocyte-specific expression was driven by 2,996 bp of $5^{\prime}$ upstream sequence from the rat $\alpha \mathrm{MyHC}$ gene (8). Five independent lines of mice were generated with the cTnT-Myc-WT sequence and nine lines of mice with the cTnT-Myc-truncation were generated. The presence of the transgene was verified by Southern blot. Western analysis of cardiac extracts prepared from cTnT-Myc-WT F1 mice revealed a high level of transgene expression in four of the five lines. Two lines were selected for further analysis and the cTnT-Myc-WT protein corresponded to $\sim 40-50 \%$ of the total cTnT in the heart (Fig. $1 \mathrm{~B}$, bottom). Despite this high level of expression, the stoichiometry of the myofibril was not altered (Fig. $1 \mathrm{C}$ ), with the transgene protein replacing a significant amount of the endogenous TnT. The apparent downregulation of endogenous contractile protein levels has been observed in other transgenic overexpressing models, where the decrease in

A

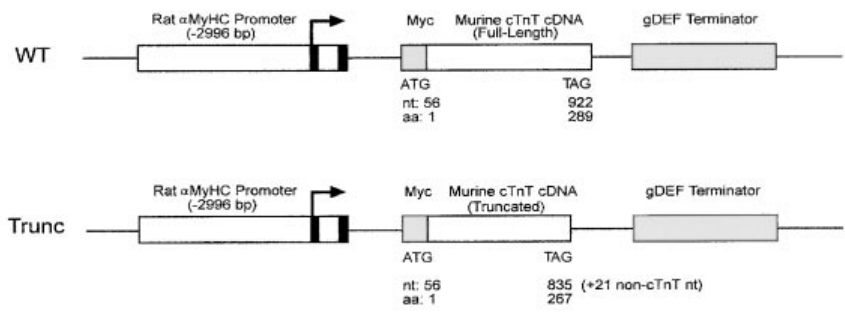

B

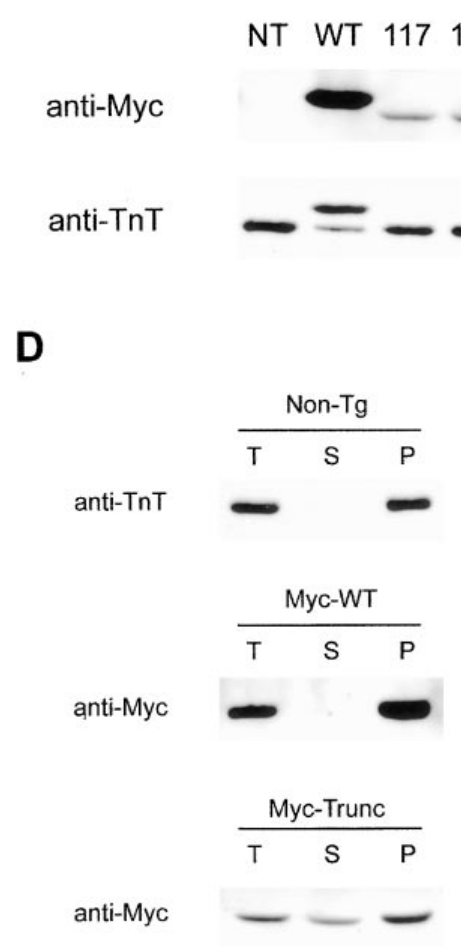

C

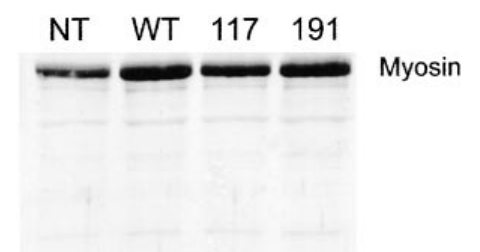

Actin / TnT

Tropomyosin

Tnl

Light Chain 1

Light Chain 2
Figure 1. Expression of cTnTMyc-WT and cTnT-Myc-truncation proteins in cardiac tissue. (A) Constructs used to generate mice expressing $W T$ and truncated (Trunc) myc-tagged cardiac TnT. (B) Western blot analysis of heart homogenates from Myc-WT, Myc-truncation, and non-Tg mice ( $5 \mu \mathrm{g}$ of total lysate) probed with antibodies, as indicated. Upper arrows indicate position of cTNT-Myc-WT and lower arrows indicate positions of endogenous cTnT and cTnTMyc-truncation proteins. $(C)$ Myofibrils were purified from mouse hearts, as indicated, and subjected to SDS-PAGE. *Refers to the cTnT-Myc-WT protein that migrates slower than endogenous cTnT because of the myc tag. (D) Fractionation of cTnT. Three separate fractions were analyzed $(T=$ total, $S=$ supernatant and $P=$ pellet $)$. Immunoblots of fractions from non-Tg, Myc-WT, and Myc-truncation heart homogenates loaded for equal signal intensity and probed with antibodies as indicated. 
endogenous protein is thought to be a mechanism by which myofibrillar stoichiometry is maintained (21). In contrast, whereas nine independent founders were generated with the cTnT-Myc-truncation construct, one founder died before producing progeny and only three of the remaining eight lines expressed the transgene, and even then, at low levels. Two of these lines were selected for further analysis and expressed $<5 \%$ of total cTnT (Fig. $1 \mathrm{~B}$, top). The amount was determined using a standard curve with purified TnT and a myc-tagged standard (data not shown). In the transgenic mice, stoichiometry in the myofibril was also unaltered (Fig. $1 C$ ). Multiple samples were scanned and there was no significant difference in any of the nontransgenic and transgenic myofibrils. In an attempt to increase mutant transgene protein expression, heterozygotes of one line were crossed, but homozygous animals died within hours after birth and no adult homozygotes have been identified (see below).

The protein domains that have been deleted in the cTnTMyc-truncation mutant are known to be involved in multiple thin filament protein interactions, and, as such, the truncated molecule may exhibit an altered myofibrillar incorporation pattern (23). To investigate this possibility further, crude heart homogenates were fractionated, and separate (and equal) aliquots from each fraction were analyzed via Western blotting. Myofibrillar components including thick and thin filament proteins pellet under such conditions. The fractionation pattern of Myc-WT, Myc-trunc, and endogenous TnT was determined (Fig. $1 \mathrm{D}$ ). To allow a direct comparison between the cTnTMyc-WT and cTnT-Myc-truncation samples, protein was loaded to generate equal signal intensity. There is much more TnT protein in the supernatant $(S)$ lane of the cTnT-Myc-truncation sample than in the equivalent lanes of the cTnT-MycWT sample or the endogenous TnT from a nontransgenic animal. This result suggests that the truncated molecule has an altered affinity for and/or stability within the sarcomeric apparatus.

Mice expressing higher levels of cTnT-Myc-truncation protein have limited survival. A classic feature of cTnT-related FHC is a high frequency of sudden death at an early age $(4,5)$. To determine whether survival was affected in transgenic mice, the genotypes of two separate groups of animals resulting from crosses of heterozygous line 117 mice were determined at birth and as adults (4-10 wk of age). Given that it has been suggested that the FHC alleles function via a dominant negative mechanism, we reasoned that transgene dose might affect viability. Genotypes of 16 independent litters were determined within $6 \mathrm{~h}$ of birth or after weaning (4-10 wk). The genotype ratios of animals killed immediately after birth $(n=$ 60) were clearly Mendelian (Fig. 2 A). However, no homozygous mice lived for $>24 \mathrm{~h}$, with the majority either stillborn or dying within the first few hours of life. 48 adult mice were screened (representing seven separate litters) and no homozygous animals were identified (Fig. $2 B$ ). To ascertain whether the homozygotes that exhibit perinatal lethality express greater amounts of cTnT-Myc-truncation protein, heart homogenates were prepared from the litters of heterozygous matings within $5 \mathrm{~h}$ of birth and subjected to Western analysis. As expected, the homozygous offspring have approximately twice as much cTnT-Myc-truncation protein as do their heterozygous littermates (data not shown). Thus, the cTnT-Myctruncation allele functions as a strong dominant negative mutant and viability is correlated with the amount of transgene
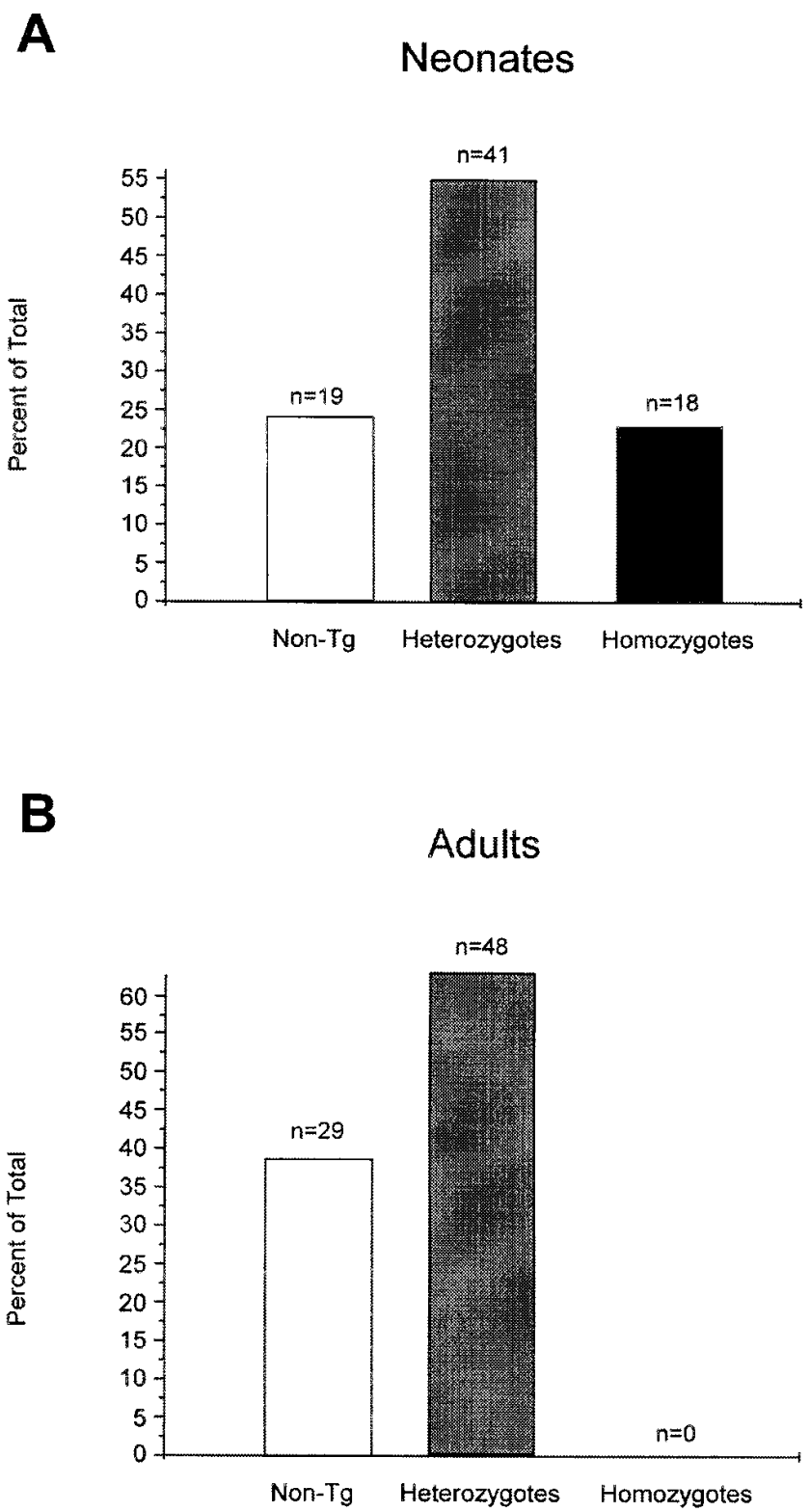

Figure 2. Survival rates of cTnT-Myc-truncation mice. Genotype distribution for 10 separate litters is plotted as percentage of total births for each group. Animals were screened at birth (Neonates) or after weaning (Adults). The Neonates grouping includes three stillborn animals. (A) Animals genotyped immediately after birth (Total $n=60$ ). (B) Animals genotyped at age $>3 \mathrm{wk}$ (Total $n=48$, representing 7 litters).

protein. Lifespan in heterozygous mice of line 191 (which express slightly more transgene than line 117) has appeared to be normal with the following exception. No heterozygous male mouse that has served as a stud has survived $>13$ mo.

Cardiac TnT-Myc-truncation mice exhibit decreased ventricular mass and atrial hypertrophy. It is well established that most patients with cTnT-related FHC generally exhibit mild or no apparent ventricular hypertrophy yet have a high frequency of sudden death $(4,5)$. However, there are exceptions, such as one reported patient with massive hypertrophy (10). Examination of heart weight to body weight ratios among non-Tg, cTnT-Myc-WT, and cTnT-Myc-truncation mice revealed a 
A

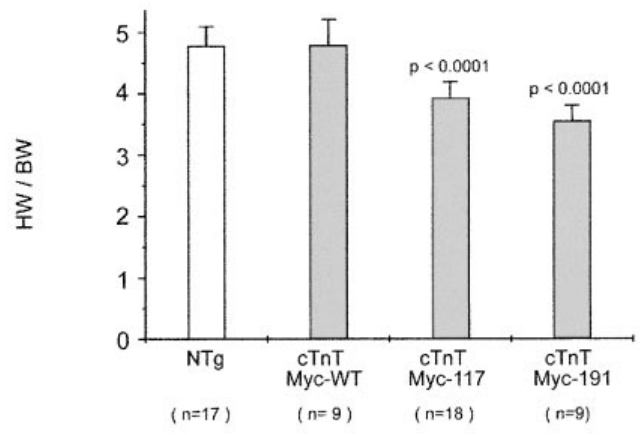

B

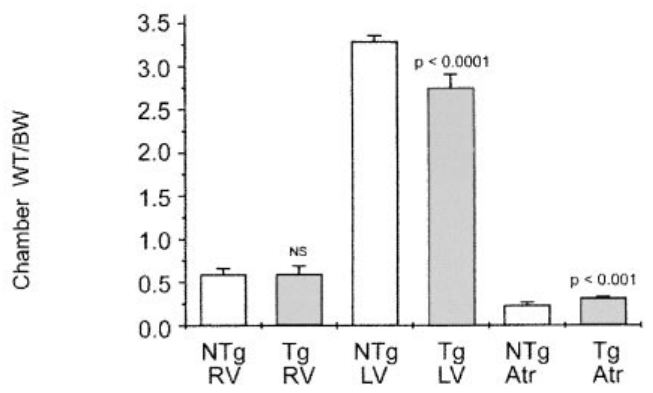

C

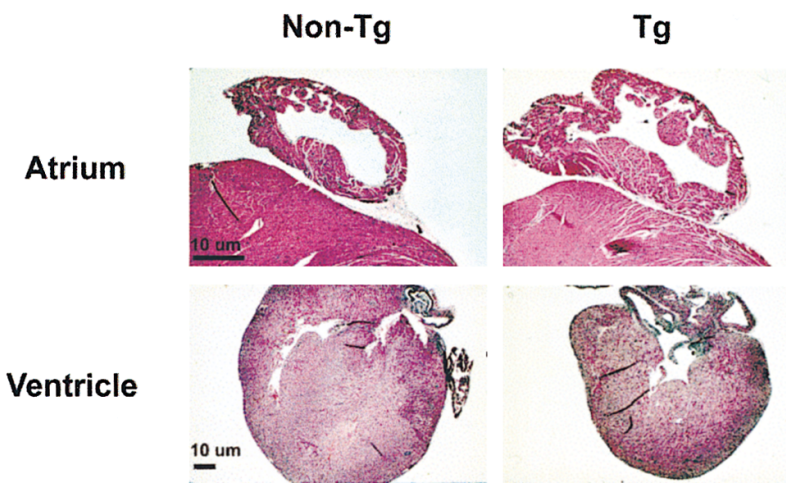

Figure 3. Mice heterozygous for the cTnT-Myc-truncation allele exhibit decreased ventricular mass. $(A)$ Whole heart weight to body weight ratios ( $\mathrm{mg}$ heart or chamber weight/gms body weight $(B W)$ in 4-5-mo-old animals. Error bars represent SD from the mean. $P$ values are versus both N-Tg and cTnT-Myc-WT mice (Student's unpaired $t$ test). (B) Individual chamber weight to body weight ratios in 5-mo-old animals. A matched set of $6 \mathrm{~N}-\mathrm{Tg}$ and $6 \mathrm{Tg}$ (line 117) hearts were dissected into individual chambers and weighed. $R V=$ right ventricle, $L V=$ left ventricle and intraventricular septum, $A T R=$ left and right atria. $N S=$ not significant. $(C)$ Atrial hypertrophy in 5-mo-old heterozygous cTnT-Myc-truncation mice. Representative cross-sections from paraffin-embedded hearts stained with hematoxylin and eosin $(63 \times)$. Whole heart sections $(23 \times)$ are provided for comparison.

consistent $18-27 \%$ decrease in heart mass in both independent lines of cTnT-Myc-truncation mice at 4-5 mo of age when compared to either nontransgenic siblings or the cTnT-MycWT mice. Fig. $3 A$ shows the ratio of heart weight to body weight. The decrease in mass was also found to be significant when absolute heart weights were compared between lines. This decrease in heart mass was also seen in animals as young as $6 \mathrm{wk}$ and as old as $7-8 \mathrm{mo}$ old (data not shown). It is important to note that despite a $40-50 \%$ replacement of the endogenous cTnT by a myc-tagged WT protein in the cTnT-Myc-WT line, their ventricular mass is virtually identical to the non- $\mathrm{Tg}$ mice. Thus, the cardiac phenotype displayed by the cTnTMyc-truncation transgenic mice is not related to the presence of the c-myc epitope. To determine whether the decrease in heart mass was global or localized to a single cardiac chamber, hearts from cTnT-Myc-truncation mice (line 117) were fully dissected and individual chamber weight to body weight ratios were derived. As shown in Fig. $3 B$, the decrease in heart mass that is found in cTnT-Myc-truncation mice is restricted to the left ventricle. The mean decrease in left ventricular mass was $17 \%$, which correlates well with the heart weight to body weight decrease of $18-27 \%$. In addition, cTnT-Myc-truncation mice exhibited a small, but statistically significant increase in atrial size as compared to non-Tg siblings. This atrial hypertrophy is clearly evident in Fig. $3 C$, where hematoxylin and eosin (H\&E)-stained heart sections from 4-mo-old non-Tg mice and the two cTnT-Myc-truncation lines demonstrate atrial wall thickening and, in the case of the line 191 animal, early dilatation.

Cardiac-TnT-Myc-truncation mice exhibit characteristic histopathological findings of FHC. One of the hallmarks of FHC in humans is a wide range of histopathological findings, including variable degrees of myocyte disorganization and hypertrophy, myocardial fibrosis, and abnormalities of the small intramural coronary arteries, although not all patients exhibit these findings (24). Although myocellular disorganization is a frequent finding in FHC patients, its extent and spatial distribution within the heart varies widely and reflects the heterogeneity of the disease. Histopathological examination of neonatal and adult hearts from cTnT-Myc-truncation mice revealed a consistent pattern of myocellular disorganization and degeneration (Fig. 4, $A-J$ ). Heart sections from neonatal cTnT-Myctruncation mice demonstrated scattered areas of myocellular disarray with many foci found in the left ventricular free wall. Higher magnification of representative areas (Fig. 4, $E$ and $F$ ) revealed marked disorganization, pleomorphic nuclei, and scattered mitotic $(F)$ and apoptotic $(E)$ figures. Notably, no evidence for myocardial fibrosis was found in neonates. In addition, comparison to a non-Tg section suggested an apparent decrease in myocyte density, which we have quantitated and will be described in more detail below. Adult heart sections (Fig. $4, G-J$ ) demonstrated focal regions of disarray, myocellular degeneration, and mild loose fibrosis as well as widely pleomorphic nuclei. Both neonatal and adult heart sections from cTnT-Myc-WT mice were indistinguishable from non-Tgs (data not shown).

Cardiac gene expression in TnT-truncation mice. We wished to determine whether there were any changes in expression of several cardiac genes that might give insight into the phenotypes of these mice. First, these hearts are not hypertrophic, but they clearly have histopathology characteristic of FHC. We have recently reported that a transgenic model of MyHCbased FHC shows induction of the molecular markers of hypertrophy, atrial natriuretic factor, and $\alpha$-skeletal actin, in areas of histopathology and that expression of these genes can be dissociated from hypertrophy (25). In addition, changes in 
Neonates
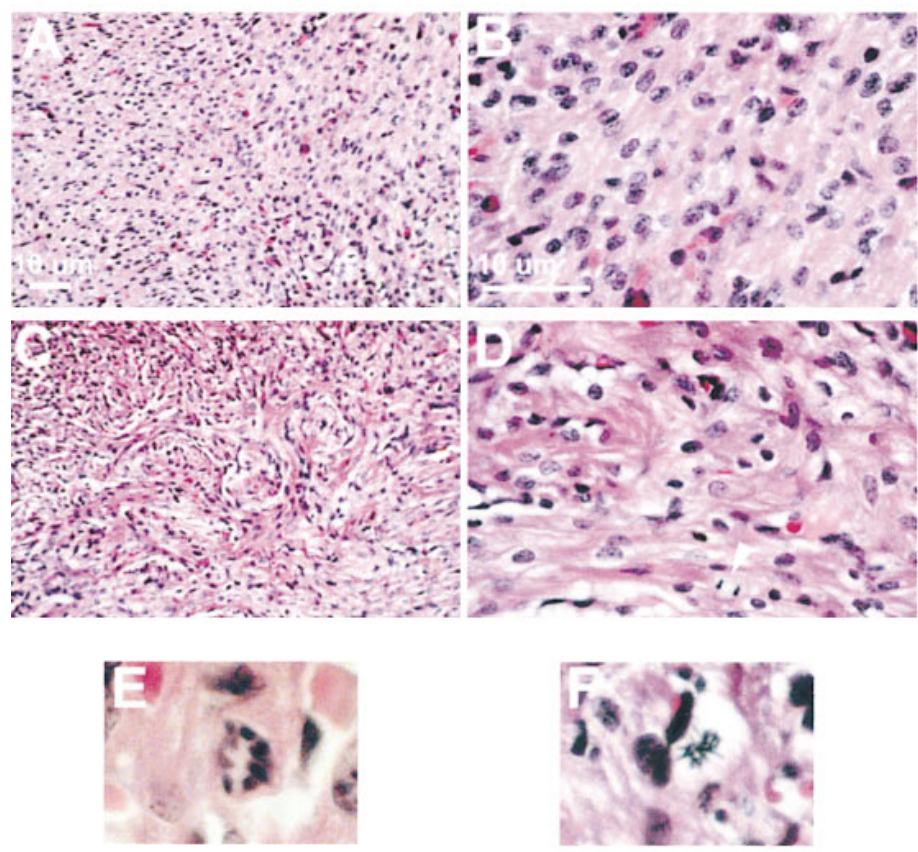

\section{Adults}

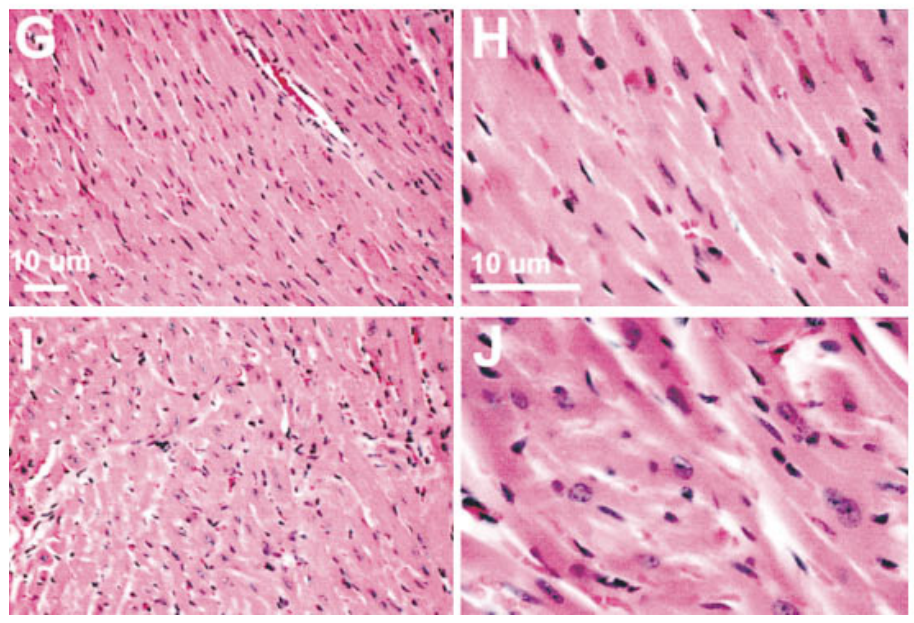

\section{Non-Tg}

\section{$\mathrm{Tg}$}

\section{Non-Tg}

Figure 4. Cardiac TnT-Myc-truncation mice display myocellular disarray and degeneration similar to that found in patients with FHC. Cardiac sections from non- $\operatorname{Tg}(A$ and $B)$ and cTnT-Myc-truncation neonatal mice $(C-F)$ were stained with $H \& E$. Scattered mitotic figures are indicated by white arrows. (160 and $400 \times$ magnification, respectively, for $A$ and $C$, $B$ and $D-E$, and $1,000 \times$ for $F)$. Non- Tg $(G$ and $H)$ and cTnT-Myc-truncation adults $(I$ and $J)$ were similarly stained.
MyHC gene expression (an increase in $\beta$ MyHC) have been reported in heart failure and in cardiac atrophy $(26,27)$, and may be partially responsible for altered systolic function. Finally, we wished to examine expression of SERCA2, as decreases in its expression have been reported in human heart failure and have been hypothesized to result in altered diastolic function (28). Northern blot analysis demonstrated no changes in expression of $\beta \mathrm{MyHC}$ or SERCA2 (Fig. $5 A$ ). Therefore, alterations in expression of these genes do not contribute to the phenotypes in these mice. This Northern blot was also hybridized with a cTnT probe that will detect both the endogenous cTnT and the transgene. As demonstrated, all three transgenic lines overexpress the cTnT mRNA, but the total amount of TnT protein remains unaffected (Fig. 5 B, TnT antibody).
Two mechanisms result in the decreased ventricular mass found in cTnT-Myc-truncation mice. Careful examination of neonatal H\&E-stained sections (Fig. 4) suggested that there was an overall decrease in cell density in sections from cTnTMyc-truncation mice. Total cell and cardiac myocyte nuclear density from neonatal heart sections were determined (Fig. 6). $A-C$ are representative $\mathrm{H} \& \mathrm{E}-$ stained neonatal heart sections from three animals and clearly demonstrate the aforementioned disarray and myocellular degeneration, as well as an apparent decrease in cell density. The number of myocytes were determined from frozen sections from two neonatal animals per line (non-Tg versus Tg-117 versus Tg-191). Myocyte numbers were then determined (see Methods). Equal cross-sectional areas were measured for non-Tg and Tg animals. There 
A

\section{Emb NT WT 117191}

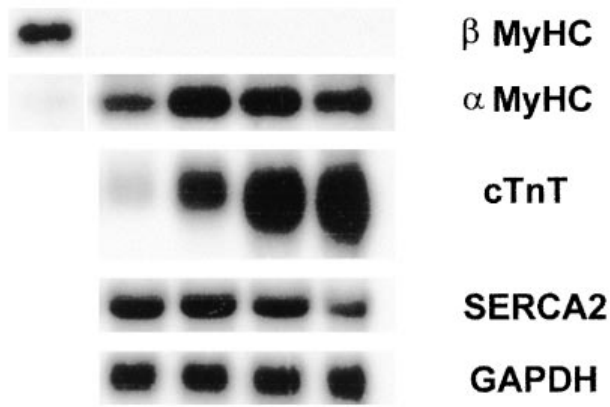

B

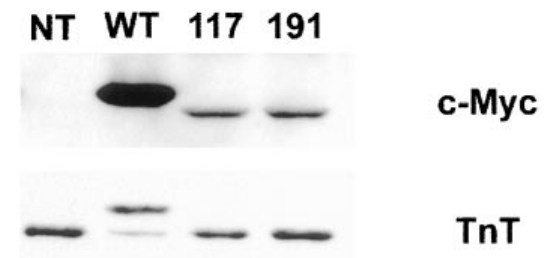

Figure 5. Adult cTnT-Myc-truncation mice do not demonstrate changes in gene expression associated with hypertrophy or failure. $(A)$ Northern blot analysis of total RNA isolated from non-Tg, WTMyc, and two independent cTnT-Myc-truncation lines (117 and 191) at 4-5 mo of age. Emb = day $16 \mathrm{pc}$ embryonic RNA (a positive control for $\beta M y H C$ ). The blot was serially hybridized with $\beta \mathrm{MyHC}$ and $\alpha \mathrm{MyHC}$ oligonucleotides and GAPDH, cTnT, and SERCA 2 cDNA probes as described in Methods. $(B)$ Western blot analysis of homogenates ( $5 \mu \mathrm{g}$ total lysate) from the same hearts as shown in $A$, probed with antibodies as indicated.

were clearly fewer myocytes in sections from cTnT-Myc-truncation animals (Fig. 6, E-F). The resultant myocyte numbers were normalized to the total number of cells per field. As shown in Fig. 6 G, hearts from both lines 117 and 191 had $\sim 8-10 \%$ fewer myocytes than non-Tg animals. These results show that the decrease in ventricular mass observed in cTnTMyc-truncation animals is due at least in part to a selective loss of cardiac myocytes that occurs before birth. This myocyte cell loss may be the stimulus that results in the ventricular remodeling seen in the cTnT-Myc-truncation animals.

As shown in Fig. 3, the overall decrease in ventricular mass

Table I. Means \pm SEM of Measured Cardiac Parameters: Baseline Loading $(250 \mathrm{mmHg} * \mathrm{ml} / \mathrm{min})$

\begin{tabular}{lccc}
\hline & Control & Trunc-Tg & Change \\
\hline & & & $\%$ \\
Working heart & $(n=6)$ & $(n=5)$ & \\
Heart rate (beats per min) & $361 \pm 18$ & $372 \pm 16$ & +3 \\
$+\mathrm{dP} / \mathrm{dt}(\mathrm{mmHg} / \mathrm{ms})$ & $4818 \pm 346$ & $4846 \pm 325$ & +1 \\
$-\mathrm{dP} / \mathrm{dt}(\mathrm{mmHg} / \mathrm{ms})$ & $3780 \pm 165$ & $2978 \pm 333$ & $-21^{*}$ \\
& & &
\end{tabular}

$* P \leq 0.05$, transgenic versus control, unpaired Student's $t$ test. seen in cTnT-Myc-truncation animals (as determined via heart weight/body weight ratios) ranges from $18-27 \%$. Note that comparison of absolute heart weights $(n=12)$ reveals a $22 \%$ decrease in heart mass. Thus, the decreased myocyte numbers alone do not account for the observed phenotype in the transgenics. Cardiac myocytes were isolated from cTnT-Myc-truncation and non-Tg adult siblings, and length and width measurements were obtained. As compared to non-Tgs, the mean length and midpoint width of quiescent ventricular cardiac myocytes from cTnT-Myc-truncation mice were smaller by 15 and $13 \%$, respectively. Representative video capture images are shown in Fig. $6 \mathrm{H}$. Analysis of these images revealed that mean myocyte area was decreased by $17 \%$ in transgenic animals. Therefore, the decreased ventricular mass exhibited by the transgenic animals is a result of two cellular mechanisms. There are fewer cardiac myocytes and the remaining Tg myocytes are smaller than non-Tg.

Cardiac TnT-Myc-truncation mice demonstrate impaired cardiac contractility and relaxation. The genetic heterogeneity of FHC in humans is reflected in the wide range of clinical and cardiovascular physiologic profiles seen in affected patients. It has been observed that even relatively mild histopathology can result in considerable cardiac dysfunction (24). To assess the functional effect of the cTnT-Myc-truncation on the intact heart, we used an isolated work-performing heart model (29). This method determines a series of basic cardiac performance measures of contraction $(+\mathrm{dP} / \mathrm{dT})$ and relaxation $(-\mathrm{dP} / \mathrm{dT})$ in a heart subjected to variable workloads. At a baseline workload, hearts from cTnT-Myc-truncation mice demonstrated a $25 \%$ decrease in the maximal rate of relaxation when compared to non-Tg siblings (Table $\mathrm{I} ;-\mathrm{dP} / \mathrm{dT}$ ). The rate at which left ventricular pressure increases $(+\mathrm{dP} / \mathrm{dT})$ is very dependent on volume (preload) and is also a good indicator of cardiac contractility. Thus, both diastolic (relaxation) and systolic (contraction) performance can be assessed by increasing the volume load on the heart. Altering the physiologic load on the cTnT-Myc-truncation hearts demonstrated a significant impairment in relaxation relative to the non- $\mathrm{Tg}$ animals and, to a lesser extent, on contractility (Table II; Fig. 7).

The direct relationship of muscle fiber length to force generation is the Frank-Starling effect and is a basic tenet of cardiac function. In a normal heart, the relationship between work and contraction/relaxation is linear (Fig. 7, $A$ and $C$ ). Hearts from cTnT-Myc-truncation mice showed a moderately good correlation $(r=0.55)$ of $+\mathrm{dP} / \mathrm{dT}$ to increased work as compared to controls (Fig. 7 B). However, the slope of the Starling curve was severely decreased in transgenics during relaxation $(r=0.18)$ suggesting that hearts from these animals

Table II. Means \pm SEM of Measured Cardiac Parameters: Starling Loading $(100-600 \mathrm{mmHg} * \mathrm{ml} / \mathrm{min})$

\begin{tabular}{lccc}
\hline & Control & Trunc-Tg & Change \\
\hline & & & $\%$ \\
Working heart & $(n=6,49)$ & $(n=5,35)$ & \\
Heart rate (beats per min $)$ & $372 \pm 5$ & $342 \pm 12$ & $-8^{*}$ \\
$+\mathrm{dP} / \mathrm{dt}(\mathrm{mmHg} / \mathrm{ms})$ & $6628 \pm 242$ & $5690 \pm 136$ & $-14^{* *}$ \\
$-\mathrm{dP} / \mathrm{dt}(\mathrm{mmHg} / \mathrm{ms})$ & $4863 \pm 126$ & $3384 \pm 112$ & $-30^{* * *}$ \\
& & & \\
\hline
\end{tabular}

$* P \leq 0.05, * * P \leq 0.01, * * * P \leq 0.001$, transgenic versus control, unpaired Student's $t$ test. 


\section{Non-Tg}
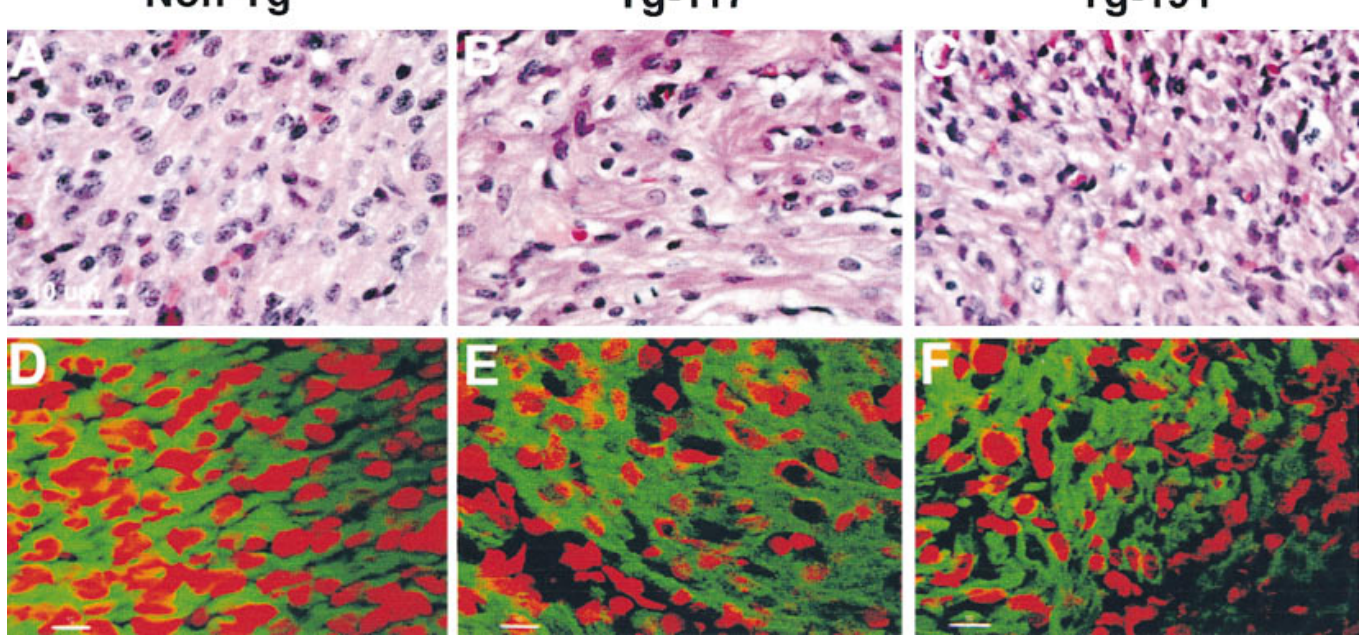

G

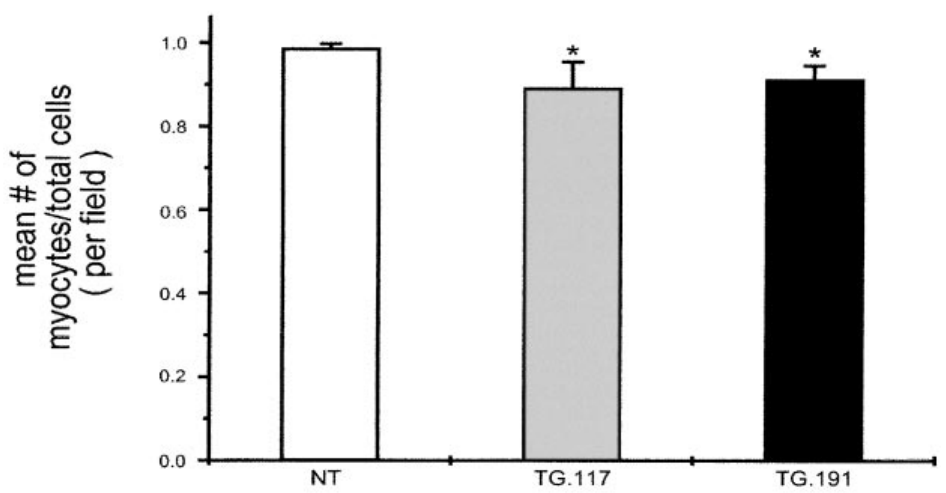

H

Non-Tg

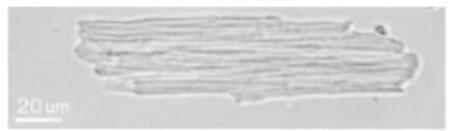

Length: $134.5 \pm 23$ um Width: $30.6 \pm 8.1 \mathrm{um}$ $n=108$
$\operatorname{Tg}-117$

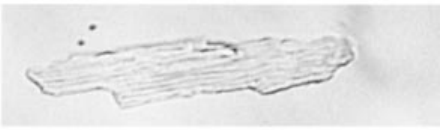

Length: $114.3 \pm 20.6^{*}$ um Width: $26.7 \pm 6.3^{\star}$ um $\mathrm{n}=106$
Figure 6. Neonatal cTnT-Myc-truncation mice demonstrate a decrease in cardiac myocyte density and size. Myocyte density determination: Neonatal hearts were isolated as described in Methods. Paraffin-embedded heart sections stained with H\&E $(A-C)$. Note the decreased cellularity and myocellular disarray in transgenic sections $(B-C)$. Frozen sections (from different mice), which were double-stained with PI and F59 to identify all cells and myocytes, respectively $(D-F)$. $(G)$ The ratio of cardiac myocytes to total cells (per field, here each field $=0.014$ $\mathrm{mm}^{2}$ ) for each line is shown. Numbers are expressed as mean $\pm \mathrm{SD}$ for $n=8$ (sections). $* P \leq$ 0.0008. (H) Myocyte size determination: Quiescent ventricular cardiac myocytes from trunc- $\mathrm{Tg}$ animals and non-Tg siblings were isolated and measured as described. Two representative video images are shown. Values are expressed as mean \pm SD, where $n=108$ and 106 , respectively. $* P<0.001$. are unable to respond to an increased work load by shortening their relaxation time $(7 D)$.

Thus, the cTnT-Myc-truncation mice exhibit significant impairment in the ability of the heart to relax in the absence of measurable cardiac hypertrophy. In FHC patients with MyHC mutations, the finding of impaired relaxation ("diastolic dysfunction") is usually a consequence of a hypertrophied left ventricle. Although the cTnT-Myc-truncation mice do exhibit an altered left ventricle (LV) geometry, their hearts are not hypertrophied. Impaired cardiac relaxation in cTnT-Myc-truncation mice in the absence of demonstrable hypertrophy may involve a secondary cellular mechanism, perhaps involving intracellular $\mathrm{Ca}^{2+}$ homeostasis.

Because electrocardiogram abnormalities have been reported to occur variably in patient populations, we wished to determine whether there were any such abnormalities in TnTMyc-truncation mice. Telemetry devices were implanted and recordings made. No differences were detected between WT and truncation-TnT mice (data not shown).

Adult cardiac myocytes isolated from cTnT-Myc-truncation hearts demonstrate calcium hypersensitivity. As an initial step to elucidate possible intracellular mechanisms that would account for the impaired diastolic function of cTnT-Myc-truncation hearts, numerous attempts were made to isolate adult cardiac myocytes from $\mathrm{Tg}$ animals to analyze their contractile properties. All experiments on non-Tg controls $(n=6)$ using the described protocol (see Methods) resulted in a high yield of healthy, rod-shaped myocytes from which contractile measurements could be taken. In contrast, cardiac myocyte isolation from cTnT-Myc-truncation mice $(n=4)$ proceeded normally, up until the final mechanical dispersion phase of the protocol. The subsequent yield of rod-shaped cells was uniformly low, and the Tg cardiac myocytes were absolutely intolerant to increases of extracellular $\mathrm{Ca}^{2+}$ (from 10-200 $\mu \mathrm{M}$ ). The 
A

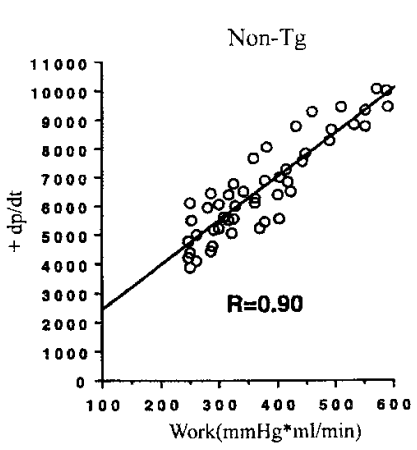

C

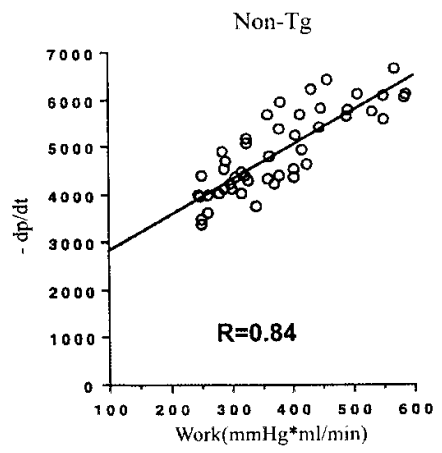

B

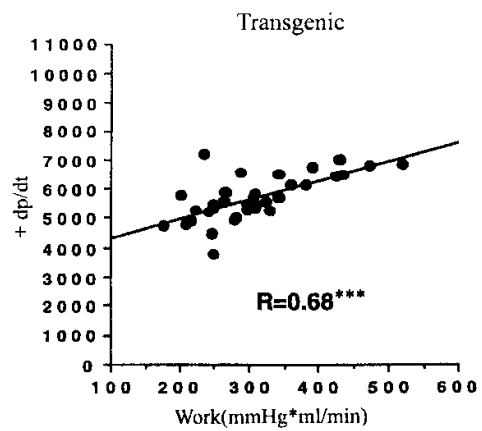

D

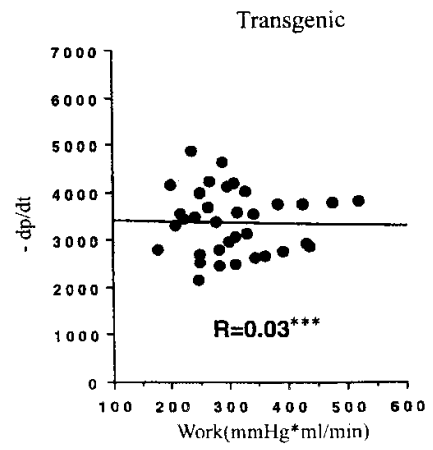

Figure 7. Cardiac TnT-Myc-truncation mice exhibit impaired cardiac function. $(A-B)$ The relative correlations between work $\left(m m H g^{*} \mathrm{ml} / \mathrm{min}\right)$ and the rate of contraction $(+d P / d T)(A)$ and relaxation $(-d P / d T)(B)$. Non-Tg animals show a strong positive correlation of $+\mathrm{dP} / \mathrm{dT}$ and $-\mathrm{dP} / \mathrm{dT}$ to increased $\mathrm{LV}$ work. Cardiac TnT-Myc-truncation mice have a decreased response of $+\mathrm{dP} / \mathrm{dT}$ to increased LV minute work and a severely decreased response of $-\mathrm{dP} / \mathrm{dT}$ to increased work. The slopes of the regression curves are significantly different between non-Tg and $\mathrm{Tg}$ and between relaxation and contraction for the $\mathrm{Tg}$ mice. $(P<0.01) R$ values are from a linear least squares fit of the data. $* * * P<0.0001$. response to the addition of $\mathrm{Ca}^{2+}$ was immediate cellular hypercontracture and death. The inclusion of BDM, in all solutions throughout the isolation procedure, was effective in producing a good yield of quiescent rod-shaped cardiac myocytes from $\mathrm{Tg}$ hearts. BDM elicits a negative inotropic effect and protects the myocardium from $\mathrm{Ca}^{2+}$ overload primarily by functioning as an excitation-contraction decoupler. This reduces releasable sarcoplasmic reticulum $\mathrm{Ca}^{2+}$ load and uncouples force generating cross-bridges (30). Removal of BDM, however, again resulted in immediate cellular hypercontracture. This is in marked contrast to the behavior in non-Tg myocytes, which tolerated the identical procedure without difficulty and were mechanically active upon subsequent pacing. The cardiac myocyte isolation procedure therefore resulted in a loss of, and an inability to reestablish competent intracellular $\mathrm{Ca}^{2+}$ homeostasis in cTnT-Myc-truncation myocytes.

\section{Discussion}

The expression of low levels of a truncated cTnT molecule previously implicated in the pathogenesis of FHC in humans results in a complex phenotype. We find decreased ventricular mass, focal myocellular disarray, and diastolic dysfunction. Our proposed mechanisms for these findings involve primary cellular and secondary geometric changes in the intact heart and may serve to help elucidate the pathogenesis of cTnTrelated $\mathrm{FHC}$ in humans. Two major findings distinguish cTnTFHC from $\beta$ MyHC-FHC: (a) all of the known cTnT disease alleles result in a similar clinical phenotype despite affecting different protein functional domains, and $(b)$ sudden cardiac death occurs at a high frequency despite the frequent presence of mild or subclinical ventricular hypertrophy (4). One of the most confounding issues regarding the pathogenesis of cTnT-
FHC has been the well established dissociation between the noninvasive clinical findings and the malignancy of the clinical phenotype. This finding is in stark contrast to the phenotype of $\beta \mathrm{MyHC}-\mathrm{FHC}$ patients, where the disease alleles fall into distinct classes of clinical severity that correlate well with the degree of hypertrophy $(31,32)$. Whether this finding simply reflects the central regulatory role played by cTnT in modulating the $\mathrm{Ca}^{2+}$ responsivity of the sarcomere (and thus is less tolerant of mutation) is currently unknown. It is clear, however, that the cTnT disease alleles do not stimulate a primary hypertrophic response and, thus, the clinical phenotype is unlikely to be solely the result of ventricular hypertrophy.

Another key issue regards the dominant negative nature of FHC. The initial report documenting the linkage of the cTnT locus to FHC suggested that the truncated allele may function as a null (11). It was reasoned that the loss of the extreme COOH-terminal region (Exons 15 and 16) and the $3^{\prime}$ untranslated region might be expected to decrease mRNA stability (33). Subsequent studies, including this report, however, have supported the hypothesis that the disease phenotype is a result of the presence of the mutant protein within the highly ordered sarcomeric structure, not simply the result of haploinsufficiency (12). Here, we present data proving that the truncated protein is expressed and that it incorporates into the myofibrillar apparatus. Although no data regarding the level of cTnTtruncation protein levels in affected patients is currently available, the expected truncated mRNA species has been detected in peripheral lymphocytes (11). However, quantitative mRNA and protein determinations from cTnT-FHC patients are still unavailable. This is an important issue because, based on the severity of the phenotype in animals expressing low levels of mutant protein, we would expect human patients to be very severely affected by a $50 \%$ replacement of cTnT with the cTnT- 
truncation molecule. In the mice described here, the relationship between the amount of mutant transgene protein and phenotype is quite clear given the early lethality seen in homozygous animals. The control (Myc-WT) mice showed no phenotype in terms of heart mass, histopathology, and myofibrillar incorporation, despite the presence of $40-50 \%$ of the total TnT as Myc-WT. This suggests that neither the Myc-tag nor the amount of Myc-WT protein had any deleterious effect.

The decreased ventricular mass found in all cTnT-Myctruncation mice is intriguing in view of the fact that both of the previously described $\beta \mathrm{MyHC}$ mouse models exhibited a clear hypertrophic response $(8,9)$. However, this result is perhaps better understood in the context of the known cTnT-FHC human phenotype where one study demonstrated significantly less hypertrophy in 67 patients with TnT mutations than in patients with $\beta \mathrm{MyHC}$ mutations (mean left ventricular free wall thickness $16.7 \pm 5.5 \mathrm{~mm}$ versus $23.7 \pm 7.7 \mathrm{~mm}$ ) (5). In another report of two pedigrees with 22 affected individuals there was no hypertrophy despite a very high incidence of sudden death (3). However, in one family of four affected individuals, two demonstrated significant hypertrophy (10). The decreased ventricular mass in the cTnT-Myc-truncation mice appears to be caused by two complementary mechanisms, both of which are the result of the presence of the cTnT-Myc-truncation protein. The first mechanism involves the primary loss of cardiac myocytes during development. Our results suggest that transgenic animals have $\sim 8-10 \%$ fewer myocytes at birth. Detailed histological analysis of neonatal hearts from cTnT-Myc-truncation animals revealed scattered foci of apoptotic, mitotic, and degenerating myocytes without evidence of active inflammation (Fig. 4, arrows). It has been well established that programmed cell death is a crucial component of the normal cardiac remodeling that occurs before birth $(34,35)$. One obvious possibility is that there may be heterogeneous expression of the cTnT-Myc-truncation protein such that myocytes expressing greater amounts are mechanically dysfunctional to such a degree that the cell undergoes programmed cell death and these myocytes are lost during development. The end result could be increased ventricular remodeling, which we have observed as foreshortening of the ventricle, particularly in neonatal homozygotes (J.C. Tardiff, unpublished observations). Apoptosis has also been shown to be involved in many normal and pathologic cardiovascular states including: pressure overload-induced hypertrophy, heart failure, cardiac remodeling, and myocyte stretch (36). Although the actual cellular mechanisms by which each of these disparate conditions result in myocyte apoptosis are not known, it is clear (particularly in the case of myocyte stretch) that mechanical changes in sarcomeric function may well result in an increase in apoptosis. Experiments are currently underway to further investigate this hypothesis.

The second mechanism for the decrease in cardiac mass found in cTnT-Myc-truncation animals is clearly the $\sim 15 \%$ decrease in myocyte size (Fig. 6). Following our model, these myocytes could represent the remaining surviving cells and may express relatively low levels of transgenic protein (as evidenced by the $<5 \%$ of total cTnT noted above). How such small amounts of the cTnT-Myc-truncation protein would result in a "smaller" myocyte remains unclear. We do not currently know whether the cells actually decrease in size or whether their normal hypertrophic growth during development is impaired. Experiments to quantitate sarcomeric length as well as to understand the contractile properties of isolated cells are currently in progress. The effects of these two mechanisms would be expected to be multiplicative, in that the overall number of myocytes in Tg animals would be $8-10 \%$ lower whereas the remaining myocytes would be $15 \%$ smaller. Thus, the expected ventricular mass of $\mathrm{Tg}$ hearts would range from $23-25 \%$ less than controls which is in good agreement with our experimental findings (Fig. 3).

We believe that the physiologic effects seen in the cTnTMyc-truncation mice are the result of both an altered ventricular geometry and an additional cellular mechanism which may involve changes in the regulation of $\mathrm{Ca}^{2+}$ homeostasis in the remaining cardiac myocytes. Although we do not know yet whether the heterozygous cTnT-Myc-truncation mice will have an overall decreased lifespan, animals which are homozygous for the truncated allele uniformly die within $24 \mathrm{~h}$ of birth. Gross examination of hearts from homozygous mice revealed a foreshortened LV (not shown), which we would expect to demonstrate impaired contractility. At birth, animals are faced with a sudden increase in systemic pressures as the adult circulatory pathway is established. A likely cause of the neonatal death seen in cTnT-Myc-truncation homozygotes is an inability to respond to these increased pressures and to maintain an adequate cardiac output.

cTnT-Myc-truncation heterozygotes demonstrate more varied and subtle changes in ventricular geometry, as no statistically significant differences in wall thickness were revealed by $2 \mathrm{D}$ echocardiographic analysis (data not shown). Hearts from these animals, however, demonstrate significantly impaired relaxation. This observation suggests that a major component of the observed diastolic dysfunction is cellular and not purely geometric. Normal relaxation at the level of the sarcomere is highly dependent on competent sarcoplasmic regulation. The fact that we could isolate cardiac myocytes from cTnT-Myc-truncation hearts only in the presence of BDM is consistent with the idea that myocyte $\mathrm{Ca}^{2+}$ regulation is altered. This would not be surprising given the central role that cTnT plays in regulating the $\mathrm{Ca}^{2+}$ responsiveness of contraction. It is not clear however, whether low levels of Tg protein would result in such a major primary effect on sarcomeric function or, in a more likely scenario, perhaps result in a maladaptive change in upstream $\mathrm{Ca}^{2+}$ handling. The fact that the hearts of mutant heterozygous mice function, albeit abnormally, suggests that the cellular phenotype may be exaggerated by the isolation procedure. Whereas BDM has been shown to affect the acto-myosin cycle, we feel that the response to $\mathrm{Ca}^{2+}$ is likely to be a reflection of a response to $\mathrm{Ca}^{2+}$ rather than an indirect effect of BDM, as the cells are not beating in the absence of an electrical stimulus.

Diagnosis and treatment of affected individuals with cTnT mutations is hampered by the lack of noninvasive clinical findings. The lack of clinical findings combined with the severity of the phenotype (sudden cardiac death in early adulthood) argue for a cellular disease mechanism. Current theories based on in vitro findings have focused on the proposed primary effect of the incorporation of the truncated molecule into the sarcomere and subsequent loss of contractile efficiency (12). Although this may well comprise the initial defect, we believe that the resultant phenotype may be due to a subsequent adaptation of the $\mathrm{Ca}^{2+}$-regulating mechanisms of the cardiac myocyte. Our observations concerning the myocyte isolation differences between the non-Tg controls and cTnT-Myc-trun- 
cation hearts are consistent with transgenic protein-mediated alterations in the cell $\mathrm{Ca}^{2+}$ or cation regulation. However, this cannot be definitively confirmed until more direct measurements of cellular $\mathrm{Ca}^{2+}$ handling can be completed. We are currently investigating the necessary cell isolation conditions that will allow more in-depth study of the cellular mechanisms involved in this complex phenotype.

The cTnT-Myc-truncation mice appear to provide a unique model system with which to investigate this apparent dissociation between gross geometric changes in the heart and the severity of the "clinical" or physiologic phenotype. These animals may yield better understanding of the interplay between sarcomeric proteins and the overall $\mathrm{Ca}^{2+}$-handling processes of the cardiac myocyte, a favorable target for human therapeutics.

\section{Acknowledgments}

The authors would like to thank Jon Lederer for suggestions concerning cardiac myocyte $\mathrm{Ca}^{2+}$ handling, M. Charlotte Olsson, Eric A. Mokelke (University of Colorado, Boulder, CO), and Inna Ginsburg (Albert Einstein College of Medicine, Bronx, NY [AECOM]) for expert technical assistance. Also, thanks to Shani Bialik and Richard Kitsis (AECOM) for discussions about apoptosis.

J.C. Tardiff would like to acknowledge the support of the Lucile Markey Foundation and the New York Academy of Medicine. This research has been supported by National Institutes of Health (Bethesda, MD) grants GM29090 and HL50560 to L.A. Leinwand; HL56370, HL41496, HL52318, and HL56620 to J. Robbins; and HL40306 and HL44146 to R.L. Moore.

\section{References}

1. Vikstrom, K.L., and L.A. Leinwand. 1996. Contractile protein mutations and heart disease. Curr. Opin. Cell Biol. 8:97-105.

2. Maron, B.J. 1996. Triggers for sudden cardiac death in the athlete. Cardiol. Clin. 14:195-210.

3. Solomon, S.D., S. Wolff, H. Watkins, P.M. Ridker, P. Come, W.J. McKenna, C.E. Seidman, and R.T. Lee. 1993. Left ventricular hypertrophy and morphology in familial hypertrophic cardiomyopathy associated with mutations of the beta-myosin heavy chain gene. J. Am. Coll. Cardiol. 22:498-505

4. Watkins, H., W.J. McKenna, L. Thierfelder, H.J. Suk, R. Anan, A. O'Donoghue, P. Spirito, A. Matsumori, C.S. Moravec, J.G. Seidman, et al. 1995. Mutations in the genes for cardiac troponin $t$ and $\alpha$-tropomyosin in hypertrophic cardiomyopathy. N. Eng. J. Med. 332:1058-1064.

5. Moolman, J.C., V.A. Corfield, B. Posen, K. Ngumbela, C. Seidman, P.A. Brink, and H. Watkins. 1997. Sudden death due to troponin T mutations. J. Am. Coll. Cardiol. 29:549-555.

6. Sata, M., and M. Ikebe. 1996. Functional anaylsis of the mutations in the human cardiac $\beta$-myosin that are resonsible for familial hypertrophic cardiomyopathy. J. Clin. Invest. 98:2866-2873.(Abstr.)

7. Sweeney, H.L., A.J. Straceski, L.A. Leinwand, and L. Faust. 1994. Heterologous expression of a cardiomyopathic myosin that is defective in its actin interaction. J. Biol. Chem. 269:1603-1605.

8. Vikstrom, K.L., S.M. Factor, and L.A. Leinwand. 1996. Mice expressing mutant myosin are a model for hypertrophic cardiomyopathy. Mol. Med. 2: 556-567.

9. Geisterfer-Lowrance, A.A.T., M. Christe, D.A. Conner, J.S. Ingwall, F.J. Schoen, C.E. Seidman, and J.G. Seidman. 1996. A mouse model of familial hypertrophic cardiomyopathy. Science. 272:731-734.

10. Forissier, J.F., L. Carrier, G. Bonne, J. Bercovici, P. Richard, B. Hainque, P.J. Townsend, M.H. Yaconb, S. Faure, et al. 1996. Codon 102 of the cardiac troponin $\mathrm{T}$ gene is a putative hot spot for mutations in familial hypertrophic cardiomyopathy. Circulation. 94:3069-3073.

11. Thierfelder, L., H. Watkins, C. MacRae, R. Lamas, W. McKenna, H.P. Vosberg, J.G. Seidman, and C.E. Seidman. 1994. $\alpha$-Tropomyosin and cardiac troponin T mutations cause familial hypertrophic cardiomyopathy: a disease of the sarcomere. Cell. 77:701-712.
12. Watkins, H., C.E. Seidman, J.G. Seidman, H.S. Feng, and H.L. Sweeney. 1997. Expression and functional assessment of a truncated cardiac troponin t that causes hypertrophic cardiomyopathy. J. Clin. Invest. 98:24562461.

13. Lin, D., A. Bobkova, E. Homsher, and L.S. Tobacman. 1996. Altered cardiac troponin $\mathrm{T}$ in vitro function in the presence of a mutation implicated in familial hypertrophic cardiomyopathy. J. Clin. Invest. 97:2842-2848.

14. Evan, G.I., G.K. Lewis, G. Ramsey, and J. Bishop. 1985. Isolation of monoclonal antibodies specific for human c-myc proto-oncogene product. Mol. Cell. Biol. 5:3610-3616.

15. Tantravahi, J., M. Alvira, and E. Falck-Pedersen. 1993. Characterization of the mouse $\beta^{\text {maj }}$ globin transcription termination region: a spacing sequence is required between the poly(A) signal sequence and multiple downstream termination elements. Mol. Cell. Biol. 13:578-587.

16. Hogan, B., F. Constantini, and E. Lacy. 1986. Manipulating the Mouse Embryo: A Laboratory Manual. Cold Spring Harbor Laboratory, Cold Spring Harbor, NY.

17. Solaro, R.J., D.C. Pang, and N. Briggs. 1971. The purification of cardiac myofibrils with triton X-100. Biochim. Biophys. Acta. 245:259-262.

18. Laemmli, U.K. 1970. Cleavage of structural proteins during the assembly of the head of bacteriophage T4. Nature. 227:680-685.

19. Chomczynski, P., and N. Sacci. 1987. Single-step method of RNA isolation by acid guanidinium thiocyanate-phenol-chloroform extraction. Anal. Biochem. 162:156-159.

20. Gulick, J., T.E. Hewett, R. Klevitsky, S.H. Buck, R.L. Moss, and J. Robbins. 1997. Transgenic remodeling of the regulatory myosin light chains in the mammalian heart. Circ. Res. 80:655-664.

21. Wolska, B.M., and R.J. Solaro. 1996. Method for isolation of adul mouse cardiac myocytes for studies of contraction and microfluorimetry. Am.J. Physiol. 271:H1250-H1255.

22. Moore, R.L., T.I. Musch, R.V. Yelamarty, R.C. Scaduto, Jr., A.M. Semanchick, M. Elensky, and J.Y. Cheung. 1993. Chronic exercise alters contractility and morphology of isolated rat cardiac myocytes. Am. J. Physiol. 264: C1180-C1189.

23. Raggi, A., R.J.A. Grand, A.J.G. Moir, and S.V. Perry. 1989. Structurefunction relationships in cardiac troponin T. Biochim. Biophys. Acta. 997:135143.(Abstr.)

24. Maron, B.M., S.E. Epstein, and W.C. Roberts. 1986. Causes of sudden death in competitive athletes. J. Am. Coll. Cardiol. 7:204-214.

25. Vikstrom, K.L., T. Bohlmeyer, S.M. Factor, and L.A. Leinwand. 1998 Ventricular expression of atrial natriuretic factor is a marker for cellular pathology, not hypertrophy, in a transgenic mouse model of cardiomyopathy. Circ. Res. 82:773-778.

26. Nakao, K., W. Minobe, R. Roden, M.R. Bristow, and L.A. Leinwand. 1997. Myosin heavy chain gene expression in human heart failure. J. Clin. Invest. 100:2362-2370.

27. Iso, T., M. Arai, A. Wada, K. Kogure, T. Suzuki, and R. Nagai. 1997. Humoral factor(s) produced by pressure overload enhance cardiac hypertrophy and natriuretic peptide expression. Am. J. Physiol. 273:H113-H118.

28. Qi, M., T.R. Shannon, D.E. Euler, D.M. Bers, and A.M. Samarel. 1997. Downregulation of sarcoplasmic reticulum $\mathrm{Ca}(2+)$-ATPase during progression of left ventricular hypertrophy. Am. J. Physiol. 272:H2416-H2424.

29. Grupp, I.L., A. Subramaniam, T.E. Hewett, J. Robbins, and G. Grupp. 1993. Comparison of normal, hypodynamic, and hyperdynamic mouse hearts using isolated work-performing heart preparations. Am. J. Physiol. 265:H1401H1410.

30. Gwathmey, J.K., R.J. Hajjar, and R.J. Solaro. 1991. Contractile deactivation and uncoupling of cross-bridges: effects of 2,3-butanedionemonoxime on mammalian myocardium. Circ. Res. 69:1280-1292.

31. Watkins, H., A. Rosenzweig, D.S. Hwang, T. Levi, W. McKenna, C.E. Seidman, and J.G. Seidman. 1992. Characteristics and prognostic implications of myosin missense mutations in familial hypertrophic cardiomyopathy. $N$. Eng. J. Med. 326:1108-1114.

32. Anan, R., G. Greve, L. Thierfelder, H. Watkins, W.J. McKenna, S. Solomon, C. Vecchio, H. Shono, S. Nakao, H. Tanaka, et al. 1994. Prognostic implications of novel $\beta$ cardiac myosin heavy chain gene mutations that cause familial hypertrophic cardiomyopathy. J. Clin. Invest. 93:280-285.

33. Tanguay, R.L., and D.R. Gallie. 1996. Translational efficiency is regulated by the length of the 3' untranslated region. Mol. Cell. Biol. 16:146-156.

34. Jacobson, M.D., M. Weil, and M.C. Raff. 1997. Programmed cell death in animal development. Cell. 88:347-354.

35. James, T.N. 1994. Normal and abnormal consequences of apoptosis in the human heart. Circulation. 90:556-573.

36. Bialik, S., D.L. Geenen, M.R. Bennett, S. Sivapalasingam, W.H. Frishman, E.H. Sonnenblick, and R.N. Kitsis. 1997. Cardiac myocyte apoptosis: a new therapeutic target? In Cardiovascular Pharmacotherapeutics. W.H. Frishman and E.H. Sonnenblick, editors. McGraw-Hill, New York. 955-972. 